\title{
Risk Optimum Allocation Model using Multiple Criteria Decision Making Techniques: A Case Study of Hormoz Petrochemical In Iran
}

\author{
Mohammad Ebrahim Ebrahimi Malekshah
}

Islamic Azad University, Department of Management, Ahmad Qasir Ave, 5th Alley, Hormoz Petrochemical, Tehran, Iran

\begin{abstract}
Today, the risk is calculated as the non-separable part of projects, as, implementation a project without risk is impossible. The risks directly affect on time, cost and the project quality. They usually impose costs on projects that must be paid by owner, contractor and/or partnership. $f$, the responsibility of these risks doesn't be allot correctly among the beneficiaries, could cause the increase in the proposed prices in sales and as a result causes the increase in owner costs, because, the contractors try to decrease their risks in under taking discreetly amounts in their proposed prices to against to probably risks. for this reason, this paper gives a model for calculating the risk determination optimum relation between the sides of contract in projects, in contracting stage, as that the compatible of the sides be absorbed as much as possible and the winner-winner relation be made between them.
\end{abstract}

Keywords: Risk optimum determination, risk, multiple-criteria making decision techniques, risk prioritize

\section{Introduction}

The root of risks in projects is because of lack of confidence in all the projects [1] and in this line the project risk is defined as below:

Unsure happening or condition that if occurs will have positive or negative affect on the goal of project [2]. The risk can be manageable, reducible, movable, and/or acceptable, but is not connived. So, the risk management is an important tool for facing the project risks. [3]. Point of view of PMBOK standard the risk management could be defined as below:

The risk management is a systematic process in recognition, analysis and reaction to project risk and is used for preparing the prefaces of positive facts and reducing the probability of occurring or the affect of catastrophic incidents on the goals of project [12]. The project risk, is an innate phenomenon of the project, so, it should be managed. So the project risk management has been defined as below:

This is a systematic planning process for recognition, analysis, answering and under minding the project risk. This management includes processes, tools and techniques that helps the manager increase the probability of positive incident results and reducing the probability of harmful incident results. [2]

Using the complete project risk management process we can state that this is the manager of the project that is aware of the project conditions, not the other persons that make themselves wedded to the conditions and happenings of management. As said by Chapman and Ward, the main goal of project risk management is to recover the function of project via recognition, evaluation and systematic project management related to risk [4]. The risk management has been introduced by project management institution as 1 of 8 main levels of generalities of project management knowledge
[5]. In the definition of this organization the project risk management has been divided to different phases. (Figure1)

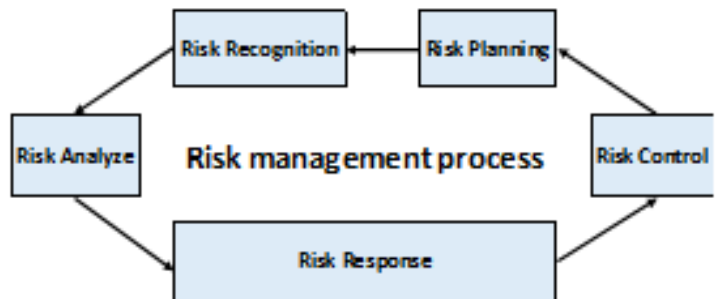

Figure 1: Risk Management Process

The project management process has different stages and layers that are repeating permanently and forwardly in different phases of project and activities like collecting information, using the devices and analysis are done for each stage [6].

\section{Risk Literature Review}

\subsection{Multiple Criteria Decision Making Technique (MCDM) in Risk Management Process}

The researches in preferences could be divided into 2 main groups, including preferences in no-confidence conditions and preferences in confidence conditions and the preferences function is called as utility function in no-confidence conditions and as value function in confidence conditions [10]. Because of the probably feature of the topic of discussion of this paper, the utility function has been used for indicating the preferences relations. 


\section{International Journal of Science and Research (IJSR) \\ ISSN (Online): 2319-7064 \\ Index Copernicus Value (2013): 6.14 | Impact Factor (2014): 5.611}

\subsection{Review of other Papers}

Table 1: Review of other papers

\begin{tabular}{|l|l|l|}
\hline Writer & Year & Abstract \\
\hline Ashley & 1980 & $\begin{array}{l}\text { Finding the proper relation of } \\
\text { cost sharing point of View of } \\
\text { employer }\end{array}$ \\
\hline $\begin{array}{l}\text { The works of } \\
\text { general contractors } \\
\text { society members } \\
\text { and the American } \\
\text { Engineering } \\
\text { companies Council }\end{array}$ & 1998 & $\begin{array}{l}\text { The expert person is asked to } \\
\text { give his idea about Determining } \\
\text { the responsible of risks, respect } \\
\text { to The job background and his } \\
\text { subjective criteria and Or the } \\
\text { pre-determined criteria by the } \\
\text { questioner }\end{array}$ \\
\hline Kamal Alsobhi & 1998 & $\begin{array}{l}\text { - Determining the winner } \\
\text { relation-winner by negotiation } \\
\text { - Under minding the real cost of } \\
\text { project completion as Discrete } \\
\text { random variable (calculating the } \\
\text { employer's and contractor's } \\
\text { Expected utility only for 3 } \\
\text { amounts of real cost. Use one } \\
\text { criteria utility function }\end{array}$ \\
\hline
\end{tabular}

\section{Problem Modeling}

\subsection{Determination of owner cost function and contractors profit:}

By agreement between owner and contractor on division of real cost of doing the project from the contracted price and under minding the risk allocation relation in owner paid cost formulas and the contractors received profit, the formulas could be written as below:

Relation 1: $C=x+b+\rho_{c}\left(x_{0}-x\right)$

Relation 2: $\boldsymbol{\rho}=b+\rho_{c}\left(x_{0}-x\right)$

$C$ : the cost that owner must pay. $p$ : contractor's received profit

$x_{0}$ : goal cost (the contract price without under minding the contractor's profit)

$x$ : the real cost of doing the project $b$ : the profit of goal $p_{c}$ : the contractor's participation share in handling the risk

This is clear that $P_{o}$ is the owner's participation share in handling the risk and is equal with $\mathrm{p}_{0}=1-\mathrm{p}_{\mathrm{c}}$.

\subsection{Model Algorithm}

The benefit of proposed model is that gaining the utility obtained by doing each project point of view of owner and contractor under minds this criterion as unit and measures the scale of consenting gained by doing each project. Of the other benefits of this model is the possibility of calculating the real cost of the expected case in every selective stage and using this quantity the contractor can predict the share of risk division which losses for that and figure (2) indicates the proposed model algorithm:

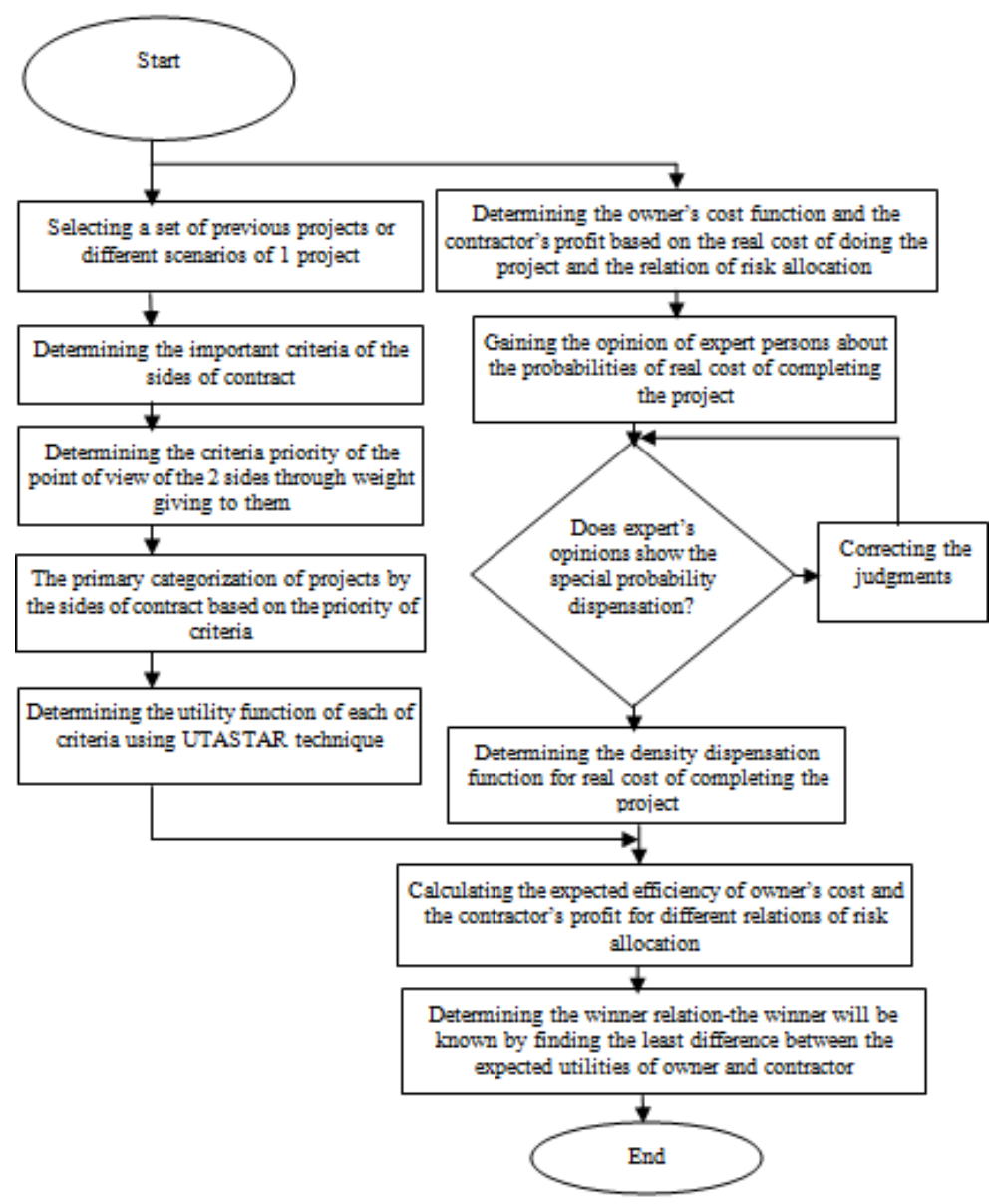

Figure 2: Model algorithm proposed 


\section{International Journal of Science and Research (IJSR) \\ ISSN (Online): 2319-7064}

Index Copernicus Value (2013): 6.14 $\mid$ Impact Factor (2014): 5.611

\section{The Presentation of Proposed Model}

Determining the utility function requires information of the decision-maker person, Herein the information of 15 previous projects that have been done in Hormoz Petrochemical Company is used.

Table 2: Using data's in utility function determining

\begin{tabular}{|c|c|c|c|c|c|c|c|c|c|}
\hline $\begin{array}{c}\frac{\tilde{U}}{0} \\
\frac{0}{0} \\
\end{array}$ & $\stackrel{\Xi}{\Xi}$ & है & 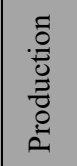 & 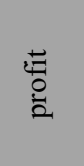 & $\frac{\bar{d}}{\frac{\tilde{d}}{0}}$ & : & $\overrightarrow{0}$ & 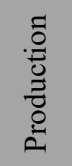 & 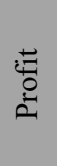 \\
\hline 1 & 60 & 1771 & 2000 & 26.65 & 9 & 38 & 1000 & 700 & 100 \\
\hline 2 & 90 & 3000 & 3900 & 900 & 10 & 96 & 3100 & 4000 & 930 \\
\hline 3 & 85 & 1870 & 2500 & 374 & 11 & 88 & 2100 & 3000 & 430 \\
\hline 4 & 80 & 1700 & 1500 & 340 & 12 & 76 & 1600 & 2200 & 320 \\
\hline 5 & 72 & 1500 & 2100 & 300 & 13 & 54 & 1100 & 1200 & 165 \\
\hline 6 & 90 & 2096 & 3400 & 62.8 & 14 & 72 & 1400 & 2000 & 210 \\
\hline 7 & 46 & 800 & 1000 & 80 & 15 & 64 & 1500 & 1400 & 225 \\
\hline 8 & 66 & 1600 & 1500 & 240 & & & & & \\
\hline
\end{tabular}

The criteria undermined by owner are cost, time and the scale of production and the contractor's criteria are profit and under minded time. The supposition is that the new contract is implemented by the goal cost of 2000 money units and 300 as contractor's profit units for producing 2300 cargo units and by the agreed time of 82 months between the owner and the contractor and the goal is finding the proper relation of risk cost allocation between the owner and the contractor.

\section{Determining owner's utility function:}

Time, cost and quality of project are known as the 3 important elements [7, 11]. Also according to below, the weight of all 3 criteria is under minded equal point of view of the owner.

\begin{tabular}{|c|c|c|c|}
\hline Scale of Production & cost & time & \\
\hline 1 & 1 & 1 & weight \\
\hline 0.333 & 0.333 & 0.333 & Normal weight \\
\hline
\end{tabular}

As far as, there is need to a primary categorization for determining the utility function conniving its way, the amounts of each of these criteria are without scale using the linear non-scaling way and then are categorized using the heavy simple additive way (SAW) and the priority of these projects has been shown based on the owner's consenting, that is the gained degrees are shown through the heavy simple additive way in table 3 .
Table 3: Ranking of Projects

\begin{tabular}{|c|c|c|c|c|c|c|c|}
\hline Rank & $\begin{array}{c}\text { Production } \\
\text { in day }\end{array}$ & cost & time & $\begin{array}{c}\text { Production } \\
\text { in day }\end{array}$ & Cost & Time Project \\
\hline 0.504 & 0.250 & 0.742 & 0.521 & 1000 & 800 & 46 & 7 \\
\hline 0.486 & 0.175 & 0.677 & 0.604 & 700 & 1000 & 38 & 9 \\
\hline 0.461 & 0.300 & 0.645 & 0.438 & 1200 & 1100 & 54 & 13 \\
\hline 0.435 & 0.500 & 0.429 & 0.375 & 2000 & 1771 & 60 & 1 \\
\hline 0.433 & 0.500 & 0.548 & 0.250 & 2000 & 1400 & 72 & 14 \\
\hline 0.430 & 0.525 & 0.516 & 0.250 & 2100 & 1500 & 72 & 5 \\
\hline 0.414 & 0.550 & 0.484 & 0.208 & 2200 & 1600 & 76 & 12 \\
\hline 0.412 & 0.850 & 0.324 & 0.063 & 3400 & 2096 & 90 & 6 \\
\hline 0.400 & 0.350 & 0.516 & 0.333 & 1400 & 1500 & 64 & 15 \\
\hline 0.390 & 0.375 & 0.484 & 0.313 & 1500 & 1600 & 66 & 8 \\
\hline 0.385 & 0.750 & 0.323 & 083.0 & 3000 & 2100 & 88 & 11 \\
\hline 0.379 & 0.625 & 0.397 & 0.115 & 2500 & 1870 & 85 & 3 \\
\hline 0.357 & 0.975 & 0.032 & 0.063 & 3900 & 3000 & 90 & 2 \\
\hline 0.333 & 1.000 & 0.000 & 0.000 & 4000 & 3100 & 96 & 10 \\
\hline 0.331 & 0.375 & 0.452 & 0.167 & 1500 & 1700 & 80 & 4 \\
\hline
\end{tabular}

The UTASTAR technique has been selected for obtaining the utility function by different criteria.[8,9,12,13] Indeed, having the utility function we can measure the utility of each new proposed project .in rest, Using the data of table 3 , the utility of each of criteria and the whole utility function s will be calculated respect to different steps of UTASTAR technique.

\section{Step 1:}

The distance between the least and the most amounts of criteria of table (2-4) is divided to equal parts. (The number of parts are determined as favorite).

$\left[\mathrm{g}_{1 *}, \mathrm{~g}_{1} *\right]=[97,87,77,67,57,47,37]$

$\left[\mathrm{g}_{2 *}, \mathrm{~g}_{2} *\right]=[3100,2640,2180,1720,1260,800]$

$\left[\mathrm{ga}_{\mathrm{a}}, \mathrm{ga}_{\mathrm{a}} *\right]=[700,1250,1800,2350,2900,3450,4000]$

Also we can write as below using linear evaluation and value of each project:

$\mathrm{U}[\mathrm{g}(7)]=0.9 \mathrm{u}_{1}(47)+0.1 \mathrm{u}_{1}(37)+\mathrm{u}_{2}(800)+0.455 \mathrm{u}_{\mathrm{a}}(700)+0.545 \mathrm{u}_{\mathrm{a}}(1250)$

Using normalization conditions, we will have the results that are below:

$u_{1}(97)=u_{2}(3100)=u_{3}(700)=0$

Also we can show the whole value of projects by $\mathrm{W}_{\mathrm{ij}}$ variables:

$\mathrm{U}[\mathrm{g}(7)]=\mathrm{w}_{11}+\mathrm{w}_{12}+\mathrm{w}_{1 \mathrm{a}}+\mathrm{w}_{14}+\mathrm{w}_{15}+0.1 \mathrm{w}_{16}+\mathrm{w}_{21}+\mathrm{w}_{22}+\mathrm{w}_{2 \mathrm{a}}+\mathrm{w}_{24}+\mathrm{w}_{25}$ $+0.545 \mathrm{w}_{\mathrm{a} 1}$

\section{Step 2\&3:}

We can have formulas and linear planning according to UTASTAR algorithm under minding $\sigma=0.025$.

Min

$=\sigma_{9}^{+}+\sigma_{9}^{-}+\sigma_{7}^{+}+\sigma_{7}^{-}+\sigma_{13}^{+}+\sigma_{13}^{-}+\sigma_{1}^{+}+\sigma_{1}^{-}+\sigma_{5}^{+}+\sigma_{5}^{-}+\sigma_{14}^{+}+\sigma_{14}^{-}+\sigma_{15}^{+}+\sigma_{15}^{-}+\sigma_{12}^{+}+$ $\sigma_{12}^{-}+\sigma_{9}^{+}+\sigma_{9}^{-}+\sigma_{6}^{+}+\sigma_{6}^{-}+\sigma_{11}^{+}+\sigma_{11}^{-}+\sigma_{2}^{+}+\sigma_{2}^{-}+\sigma_{2}^{+}+\sigma_{3}^{-}+\sigma_{10}^{+}+\sigma_{10}^{-}+\sigma_{4}^{+}+\sigma_{4}^{-}$

Which in that $\sigma^{+}$and $\sigma^{\prime}$ are respectively the errors of high approximation and low approximation.

$\boldsymbol{\Delta}(7,9)=-0.8 \mathrm{w}_{16}+0.435 \mathrm{w}_{25}+0.545 \mathrm{w}_{21}-\sigma_{7}^{+}+\sigma_{7}^{-}+\sigma_{9}^{+}-\sigma_{9}^{-}>=0.025$

$w_{11}+w_{12}+w_{19}+w_{14}+w_{15}+w_{16}+w_{21}+w_{22}+w_{29}+w_{24}+w_{25}+$

$\mathrm{w}_{\mathrm{a1}}+\mathrm{w}_{\mathrm{a2}}+\mathrm{w}_{\mathrm{9a}}+\mathrm{w}_{94}+\mathrm{w}_{\mathrm{g5}}+\mathrm{w}_{\mathrm{a}}=\mathbf{1}$

The optimum answer using Lingo software is as following: 


\section{International Journal of Science and Research (IJSR) \\ ISSN (Online): 2319-7064}

Index Copernicus Value (2013): 6.14 $\mid$ Impact Factor (2014): 5.611

$Z^{*}=0.0238$

$\mathrm{w}_{11}=0, \mathrm{w}_{12}=0.0927, \mathrm{w}_{1 \mathrm{a}}=0.0522, \mathrm{w}_{14}=0.1403, \mathrm{w}_{15}=$

$0.0179, \mathrm{w}_{16}=0, \mathrm{w}_{21}=0.1152, \mathrm{w}_{22}=0.044, \mathrm{w}_{23}=0, \mathrm{w}_{24}=$

$0.1427, \mathrm{w}_{25}=0.0575, \mathrm{w}_{21}=0, \mathrm{w}_{22}=0.1804, \mathrm{w}_{9 \mathrm{a}}=0.02, \mathrm{w}_{24}=$

$0.0343, \mathrm{~W}_{35}=0.1027, \mathrm{~W}_{36}=0$

As far as $Z^{*} \neq 0$,there is no need to do the fourth step of algorithm and the mentioned answer is optimum. Now, we calculate the utility amounts for receiving the utility function of each of criteria.

$\mathrm{u}_{1}[\mathrm{~g}(\mathrm{7})]=\mathrm{w}_{11}+\mathrm{w}_{12}+\mathrm{w}_{13}+\mathrm{w}_{14}+\mathrm{w}_{15}+0.1 \mathrm{w}_{16}=0.30310$

The amounts of marginal utility of time scale criteria

$\mathrm{u}_{2}[\mathrm{~g}(7)]=\mathrm{w}_{21}+\mathrm{w}_{22}+\mathrm{w}_{2 \mathrm{a}}+\mathrm{w}_{24}+\mathrm{w}_{25}=0.33444$

The amounts of marginal utility of cost scale criteria

$\mathrm{u}_{\mathrm{g}}[\mathrm{g}(\mathrm{7})]=0.545 \mathrm{w}_{\mathrm{g} 1}=0$

The amounts of marginal utility of production scale criteria

The above siding utilities can be normalized by $u_{i}\left(g_{i}^{j}\right)$ dividing on $u_{i}\left(g_{i}^{*}\right)$ and in this case the whole additive utility function is written as below:

$\mathrm{U}(\mathrm{g})=($

$\left.\mathrm{w}_{11}+\mathrm{w}_{12}+\mathrm{w}_{1 \mathrm{a}}+\mathrm{w}_{14}+\mathrm{w}_{15}+\mathrm{w}_{16}\right) \mathrm{u}_{1}\left(\mathrm{~g}_{1}\right)+\left(\mathrm{w}_{21}+\mathrm{w}_{22}+\mathrm{w}_{2 \mathrm{a}}+\right.$

$\left.\mathrm{w}_{24}+\mathrm{w}_{25}\right) \mathrm{u}_{2}\left(\mathrm{~g}_{2}\right)+$

$\left(w_{91}+w_{92}+w_{93}+w_{94}+w_{95}+w_{26}\right) u_{a}\left(g_{9}\right)$

Relation 3:

$\mathrm{u}(\mathrm{g})=0.3031 \mathrm{u}_{1}\left(\mathrm{~g}_{1}\right)+0.3594 \mathrm{u}_{2}\left(\mathrm{~g}_{2}\right)+0.3375 \mathrm{u}_{3}\left(\mathrm{~g}_{3}\right)$

And in add-on to that inserting the utility amounts of each criterion in statistic software's we can have their siding utility function. Herein Minitab software has been used.

And all the above said parts are doing the project by statistics $\mathrm{R}-\mathrm{Sq}$ and R-Sq (adj) in the Minitab window. Respect to the utility curves and time we find that the owner is ready for short-time projects and is unready for projects with time of 75 months.

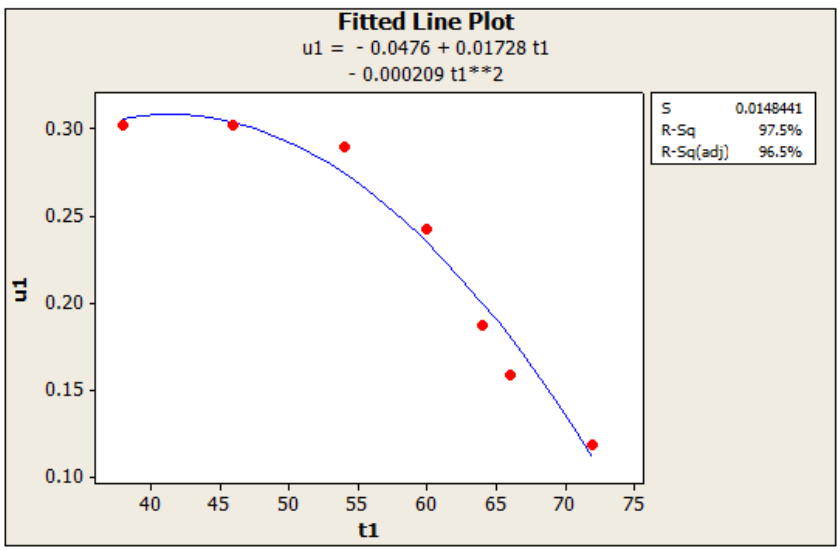

Figure 3: OTU curve for $\mathrm{t}<=75(\mathrm{OTU}=$ Owner's Time Utility)

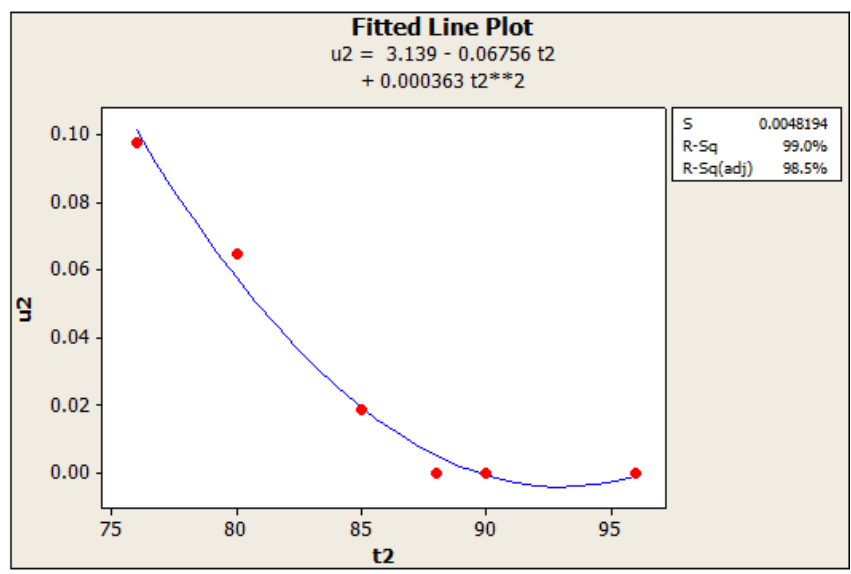

Figure 4: OUT curve for $\mathrm{t}>=75$

So the owner can be risk-accepting for low-time projects and can be risk-escaping for much-time $(t>=75)$ projects

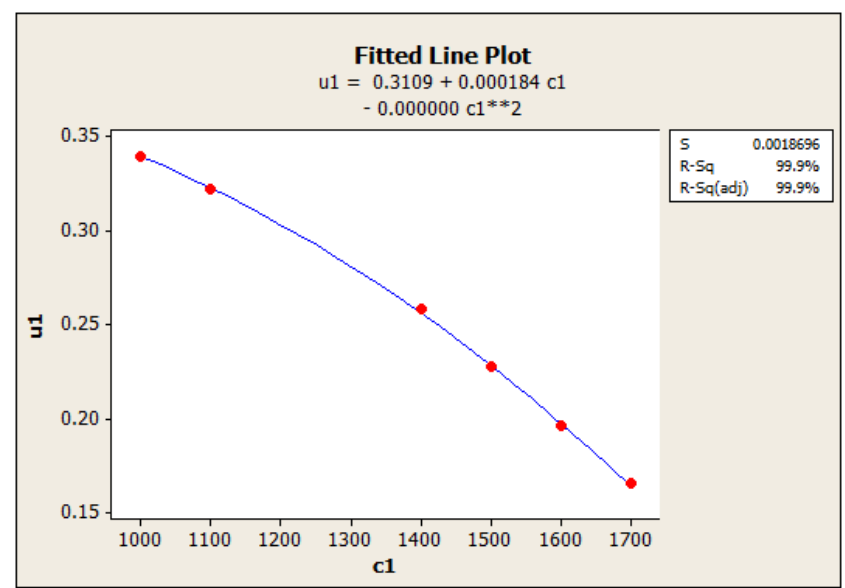

Figure 5: OCU curve for $\mathrm{c}<=1700(\mathrm{OCU}=$ Owner's Cost Utility)

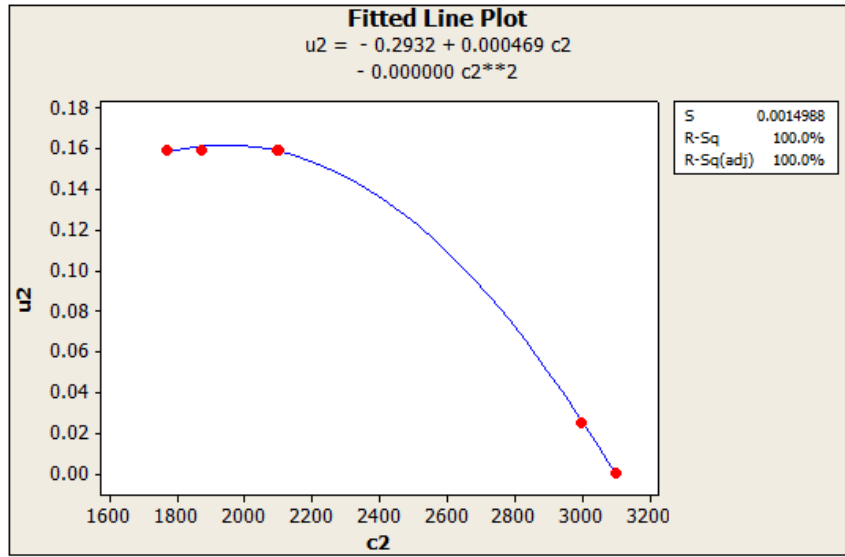

Figure 6: OCU curve for $\mathrm{c}>1700(\mathrm{OCU}=$ Owner's Cost Utility)

The above figures show that the owner's utility-cost curves are always convex, this note (point) shows the owner's riskescaping against the cost criterion. In spite of the vertexbeing of the utility curve is more in higher costs that shows the owner's more risk-escaping for more costs. 


\section{International Journal of Science and Research (IJSR) \\ ISSN (Online): 2319-7064}

Index Copernicus Value (2013): 6.14 | Impact Factor (2014): 5.611



Figure 7: OPU curve for $\mathrm{q}<=2000(\mathrm{OPU}=$ Owner's Production scale Utility)

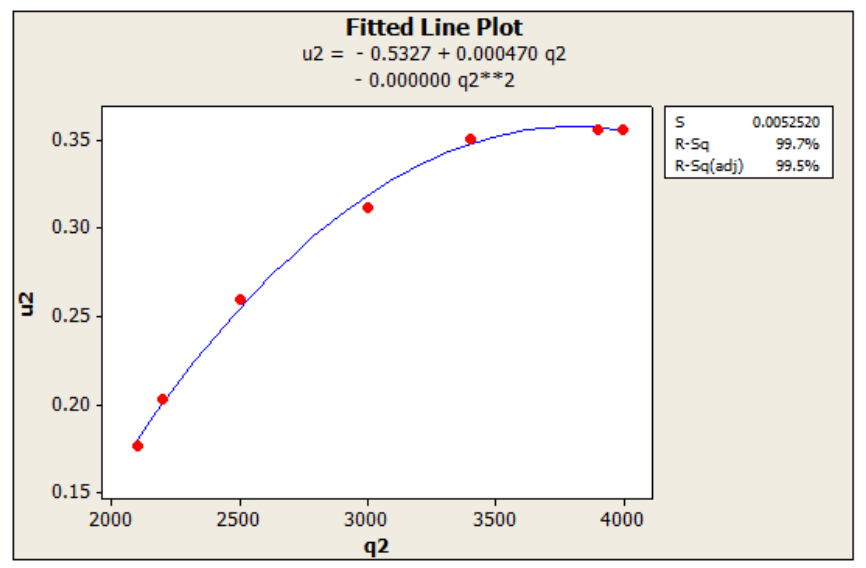

Figure 8: OPU curve for $\mathrm{q}>=2000(\mathrm{OPU}=$ Owner's Production scale Utility)

Similarly, the utility- production scale curves could be described. So, the owner is risk-accepting in producing little amounts of products and is risk-escaping in producing much amounts of product.

\section{The Contractor's Utility Function}

The contractor's utility of participating in the project, is measured by 2 criteria called, profit and time. Also, the importance of profit criterion has been under minded 2 folds of the importance of time criterion.

\begin{tabular}{|c|c|c|}
\hline Time & Profit & \\
\hline $\mathbf{1}$ & 2 & weight \\
\hline $\mathbf{0 . 3 3 3}$ & $\mathbf{0 . 6 6 7}$ & Normal weight \\
\hline
\end{tabular}

All the stages are passed for determining the contractor's utility function like the owner's utility function and by inserting the amounts of utility of each of criteria in MINITAB software their curve and siding utility function equation is gained as below.

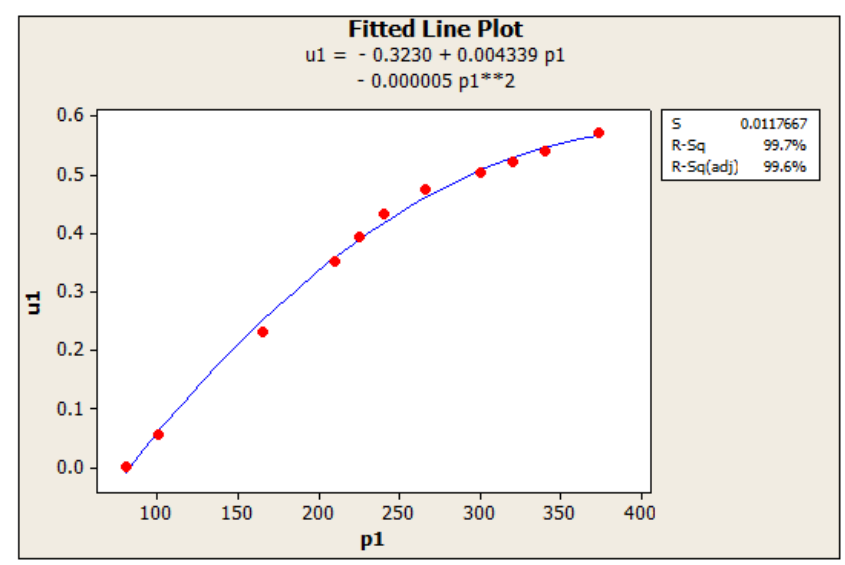

Figure 9: curve for $\mathrm{p}<=400$

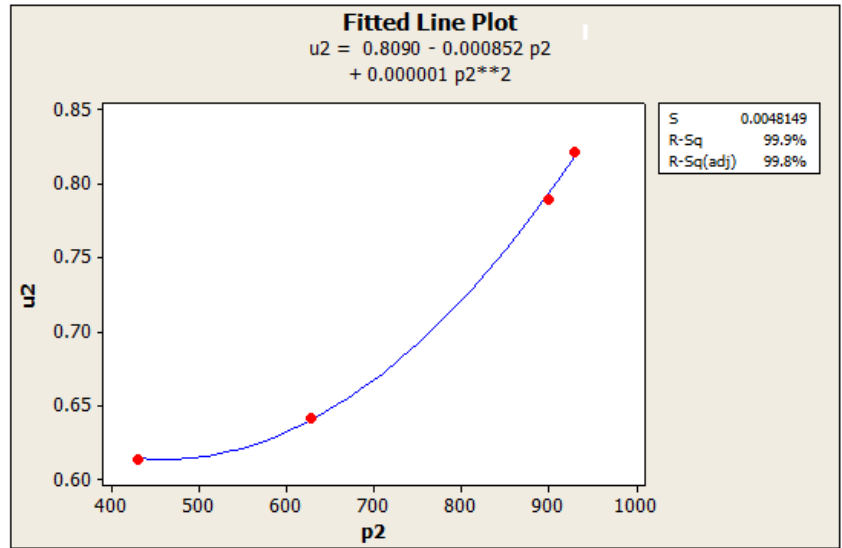

Figure 10: curve for $\mathrm{p}>400$

$(\mathrm{CPU}=$ Contractor's Profit Utility $)$

The above curves show that the assumed contractor is riskescaping for receiving little profit and is risk-accepting for receiving much profit. That is if a project be offered to this contractor with much profit he will accept the risks of doing the project and takes part in the project. But if a project be offered to this contractor with low profit will be ready for accepting the project and if the risk of doing the project be much, he won't take part in the project.



Figure 11: contractor's time utility curve

This could be understood from figure 11 which this contractor is risk-accepting related to the time that this result will be match giving less weight to the time criterion in making priority for projects. 


\section{International Journal of Science and Research (IJSR) \\ ISSN (Online): 2319-7064}

Index Copernicus Value (2013): 6.14 | Impact Factor (2014): 5.611

\section{Density Function Determination of Real Cost Probability of Completing the Project}

In this article, the expert persons' opinion will be used for achieving the probability density function of this random variable.

Table 4: The expert persons' opinion about real cost probability of completing the project with the forecasted cost

\begin{tabular}{|c|c|c|c|c|c|c|c|}
\hline Risk & Cost & Risk & Cost & Risk & Cost & Risk & Cost \\
\hline 0.02 & 3000 & 0.23 & 2500 & 0.67 & 2025 & 0.0001 & 1650 \\
\hline 0.01 & 3050 & 0.20 & 2550 & 0.65 & 2050 & 0.001 & 1700 \\
\hline 0.009 & 3100 & 0.17 & 2600 & 0.61 & 2100 & 0.1 & 1750 \\
\hline 0.008 & 3150 & 0.15 & 2650 & 0.56 & 2150 & 0.1 & 1800 \\
\hline 0.0075 & 3200 & 0.13 & 2700 & 0.49 & 2200 & 0.25 & 1850 \\
\hline 0.006 & 3250 & 0.11 & 2750 & 0.46 & 2250 & 0.35 & 1900 \\
\hline 0.005 & 3300 & 0.09 & 2800 & 0.4 & 2300 & 0.55 & 1950 \\
\hline 0.002 & 3350 & 0.07 & 2850 & 0.36 & 2350 & 0.65 & 1970 \\
\hline 0.0001 & 3370 & 0.06 & 2900 & 0.32 & 2400 & 0.7 & 2000 \\
\hline & & 0.04 & 2950 & 0.29 & 2450 & 0.69 & 2015 \\
\hline
\end{tabular}

Using the MINITAB software the accordance of GAMMA statistical dispensation has been considered on the data of table (4).

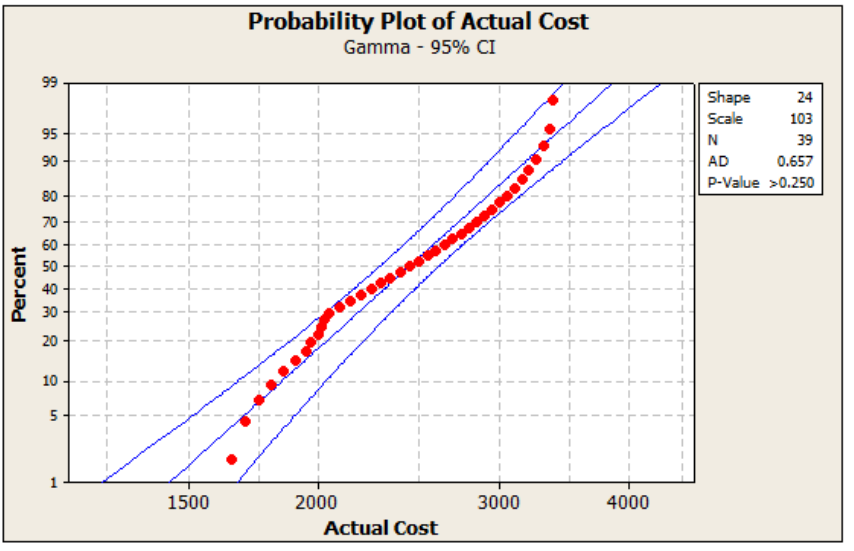

Figure 12: accordance of gamma dispensation on density function of completing the project

As it is observed in figure (12), MINITAB has drawn a confidence limitation on the chart. This confidence limitation will be drawn on the existing data as default based on assessments of under minded dispensation parameters. The dispensation parameters, the amount of ANDERSONDARLING test statistics and the amount of $p$-value and cases like that have been drawn in the chart window and the number of observations will be supervised. If the under minded dispensation be according to the data:

-the drawn points will be in the confidence distance and close to the right line.

The amount of ANDERSON-DARLING test will be small and $\mathrm{p}$ - value will have amounts bigger than $\boldsymbol{\alpha}$.

Respect to the (12) figure this is observed that the data are in the trust or confidence limitation, also the amount of ANDERSON-DARLING $(\mathrm{AD}=0.657)$ small and the amount of p-value is bigger than $\boldsymbol{\alpha}=0.1$. For this reason, the $\mathrm{x}$ goodness approximation has GAMA dispensation with the parameter of figure $\mathrm{k}=24$ and the scale parameter is $\boldsymbol{\theta}=103$.

\section{Calculating the owner expected utility:} The owner expected utility:

Attention to relation 2, the expectative value of the owner's final cost utility could be written as below:

Relation 4:

$$
E U V_{c}=E[u(c)]=\int_{-\infty}^{+\infty} u(c) f(c) d c
$$

Relation 5:

$\begin{cases}u_{z}(c)=0.0000001 c^{2}+0.000184 c+0.3109 & c \leq 1700 \\ u_{2}(c)=0.000000 c^{2}+0.000469 c+0.2932 & c>1700\end{cases}$ Relation 6:

$E U V_{c}=\int_{-\infty}^{0} u_{1}(c) f(c) d c+\int_{0}^{1700} u_{1}(c) f(c) d c+\int_{1700}^{+\infty} u_{2}(c) f(c) d c=\int_{0}^{1700} u_{1}(c) f(c) d c+\left(1-\int_{0}^{1700} u_{2}(c)\right) f(c) d c$ $\Rightarrow E U V_{c}=\int_{0}^{1700} 1 \times 10^{-7} c^{2} f(c) d c+\int_{0}^{1700} 1.84 \times 10^{-4} c f(c) d c+\int_{0}^{1700} 3.109 \times 10^{-1} f(c) d c+\left(1-\left(\int_{0}^{1700} 1 \times\right.\right.$ $10^{-7} c^{2} f(c) d c+\int_{0}^{1700} 4.69 \times 10^{-4} c f(c) d c+2.932 \times 10^{-1} f(c) d c$

This is necessary that the equation be clear by density function and $f(c)$ and what was gained in the previous part was the density function of $\mathrm{x}$ that is the real cost of doing the project. So, $\boldsymbol{C}$, is the function of $\mathrm{x}$.

So,

$$
\begin{aligned}
& x \sim \operatorname{Gamma}(k, \boldsymbol{\theta}) \sim \operatorname{Gamma}(24,103) \\
& c=x+b+\boldsymbol{\rho}_{c}\left(x_{\circ}-x\right)
\end{aligned}
$$

Also has the GAMA dispensation with $\boldsymbol{\theta}_{1}, k_{1}$ parameters.

To achieve the parameters of this new dispensation, we use the average and $\mathrm{x}$ dispensation variance and its relation with average and $\mathrm{c}$ dispensation variance. We know that the average and variance of GAMA dispensation are received by the relations below:

Relation 7:

$\mu=\mathrm{E}(\mathrm{x})=\mathrm{k} \theta=24^{*} 103=2472$

Relation 8:

$\delta^{2}=\operatorname{Var}(\mathrm{x})=\mathrm{k} \theta^{2}=24^{*} 103^{2}=25616$

Also, the relation between $\mathrm{c}$ average and variance and $\mathrm{x}$ average and variance could be received by the way below: Relation 9: $\quad \mathrm{E}[\mathrm{c}]=\mathrm{E}[\mathrm{x}]+\mathrm{b}$ $=\mathrm{p}_{\mathrm{c}} \mathrm{x}_{0}-\mathrm{p}_{\mathrm{c}} \mathrm{E}[\mathrm{x}]=\mathrm{b}+\mathrm{p}_{\mathrm{c}} \mathrm{x}_{0}+\left(1-\mathrm{p}_{c}\right) E[x]=\mathrm{k}_{1} \theta_{1}$

Relation 10: $=\left(1-\mathrm{P}_{\mathrm{C}}\right)^{2} \operatorname{Var}(\mathrm{x})=\mathrm{k}_{1} \theta_{1}{ }^{2}$

$\operatorname{Var}[\mathrm{C}]$

By placing of relations 7 and 8 in relations 9 and 10 the amounts of average and $\mathrm{c}$ dispensation variance of based on

$\boldsymbol{\rho}_{C}$ will be gained as below:

Relation 11:

$\mathrm{E}[\mathrm{c}]=\mathrm{k}_{1} \theta_{1}=2772-472 \mathrm{p}_{\mathrm{c}}$

Relation 12:

$\operatorname{Var}[\mathrm{c}]=\mathrm{k}_{1} \theta_{1}{ }^{2}=254616\left(1-\mathrm{p}_{\mathrm{c}}\right)^{2}$ 


\section{International Journal of Science and Research (IJSR) \\ ISSN (Online): 2319-7064}

Index Copernicus Value (2013): 6.14 $\mid$ Impact Factor (2014): 5.611

Table 5 shows the $\rho_{c}$ probability density function $\left\{\begin{array}{c}\mathrm{k}_{1} \theta_{1}=2724.8 \\ \mathrm{k}_{1} \theta_{1}^{2}=206238.96\end{array} \Rightarrow \theta_{1}=75.69, \mathrm{k}_{1}=36\right.$ parameters. For example for $\rho_{c}=0.1$

Table 5: C probability density function parameters for $\boldsymbol{\rho}_{C}$ different amounts

\begin{tabular}{|c|c|c|c|c|c|c|c|c|c|c|c|}
\hline $\boldsymbol{\rho}_{\boldsymbol{C}}$ & 0 & 0.1 & 0.2 & 0.3 & 0.4 & 0.5 & 0.6 & 0.7 & 0.8 & 0.9 & 1 \\
\hline $\boldsymbol{k}_{2}$ & 30.179 & 36.000 & 43.997 & 55.458 & 72.799 & 101.035 & 152.046 & 260.148 & 562.921 & 2163.787 & - \\
\hline $\boldsymbol{\theta}_{2}$ & 91.853 & 75.690 & 60.858 & 47.431 & 35.484 & 25.100 & 16.369 & 9.385 & 4.254 & 1.085 & 0 \\
\hline
\end{tabular}

Now we should be able to gain $\int c^{2} f(c) d c, \int c f(c) d c$ which in that $\mathrm{C}$ has

Relation 14:

$c^{2} f(c) \sim\left(k_{1}+1\right) k_{1} \theta_{1}^{2} G a m m a\left(k_{1}+2, \theta_{1}\right)$

the GAMA dispensation with the probability density function $f(c)$ and with the Parameters of table (5).

Relation 13:

$c \sim \operatorname{Gamma}\left(k_{1}, \theta_{1}\right) \Rightarrow f(c)= \begin{cases}\frac{c^{k_{1}-s_{1}} e^{-\frac{c}{\theta_{1}}}}{\Gamma\left(k_{1}\right) \theta_{1}^{k}} & c \geq 0 \\ 0 & c<0\end{cases}$

Now respect to the relations and the given results, we can write the owner's final cost expected value in relation (6) as below:

So after passing some stages that has been mentioned in the reference the relation 14 will be:

$$
\begin{aligned}
& \text { c } \sim \text { Gamma }\left(k_{1}+2, \theta_{1}\right) \\
& c \sim \operatorname{Gamma}\left(k_{1}+1, \theta_{1}\right) \\
& \text { c } \sim \operatorname{Gamma}\left(k_{1}, \theta_{1}\right) \\
& \overbrace{}^{2} \\
& \overbrace{}^{(\mathrm{c}=1700)} \\
& \mathrm{EUV}_{\mathrm{c}}=1 \times 10^{-7} \theta_{1}{ }^{2} \mathrm{k}_{1}\left(\mathrm{k}_{1}+1\right) \mathrm{F}(\mathrm{c}=1700)+1.84 \times 10^{-4} \theta_{1} \mathrm{k}_{1} \mathrm{~F}(\mathrm{C}=1700)+3.109 \times 10^{-1} \mathrm{~F}(\mathrm{C}=1700) \\
& \mathrm{c} \sim \mathrm{Gamma}\left(\mathrm{k}_{1}+2, \theta_{1}\right) \\
& \mathrm{c} \sim \operatorname{Gamma}\left(\mathrm{k}_{1}+1, \theta_{1}\right) \\
& \mathrm{c} \sim \operatorname{Gamma}\left(\mathrm{k}_{1}, \theta_{1}\right) \\
& \left(1-(1 \times 10^{-7} \theta_{1}{ }^{2} \mathrm{~K}_{1}\left(\mathrm{~K}_{1}+1\right) \overbrace{\mathrm{F}(\mathrm{C}=1700)}+4.69 \times 10^{-4} \theta_{1} \mathrm{~K}_{1} \overbrace{\mathrm{F}(\mathrm{C}=1700)}+2.932 \times 10^{-1} \overbrace{\mathrm{F}(\mathrm{C}=1700)}\right.
\end{aligned}
$$

In the above relation $\mathrm{F}(\mathrm{c})$ is the $\mathrm{c}$ additive dispensation function. In table 6 we showed that the $\theta_{1}, k_{1}$ amounts will be different for $\boldsymbol{\rho}_{c}$ different amounts. So, there will be gained different amounts of $E U V_{c}$ for $\rho_{c}$ different amounts.

Table 6: $E U V_{c}$ amounts for $\boldsymbol{\rho}_{C}$ different amounts

\begin{tabular}{|l|c|c|c|c|c|c|c|c|c|c|c|}
\hline $\boldsymbol{\rho}_{c}$ & 0 & 0.1 & 0.2 & 0.3 & 0.4 & 0.5 & 0.6 & $\mathbf{0 . 7}$ & 0.8 & 0.9 & 1 \\
\hline EUVc & 0.996638 & 0.997752 & 0.998680 & 0.999366 & 0.999780 & 0.999957 & 0.999997 & $\mathbf{1}$ & 1 & 1 & - \\
\hline
\end{tabular}

The whole amount of expected utility of doing the proposed project will be obtained for the owner, using relation (3). That is:

$E U V_{\text {Total }}=0.3031 E U V_{t}+0.3594 E U V_{c}+0.3375 E U V_{q}$ $q=2300>2000 \Rightarrow u(q)=0.5327+0.000470 q+0.000000 q^{2}=1.6137$

Since the production scale is set, then we will reach to the predicted production scale by probability $1(\mathrm{P}(\mathrm{q})=1)$, as a result:

$$
E U V_{q}=1.6137
$$

But because of there being the risk in the project, also, the time is a continuous random variable like the cost that its expected utility scale will be calculable like what was done about the cost criterion, while making certain contract after finding the related density function. But paying attention that the goal of this dissertation is gaining the $\rho_{c}$ optimum amount, as that $\rho_{c}$ there will be a winner-winner situation between the owner and the contractor, then the whole expected utility number amount won't be necessary. Of course, its bigness changes will be under minded by $\rho_{c}$ changes. And as far as, the $\rho_{c}$ changes are effective in $E U V_{q}$ and $E U V_{c}$ amounts, so, we connive gaining the $\mathrm{t}$ density function and calculating its expected utility for ease and summarization. And we compare the owner's and contractor's whole expected utility in $\rho_{c}$ different amounts comparing the expected utility of cost for owner and profit for contractor. 


\section{International Journal of Science and Research (IJSR) \\ ISSN (Online): 2319-7064}

Index Copernicus Value (2013): 6.14 | Impact Factor (2014): 5.611

\section{The Contractor's Expected Utility:}

$\mathrm{p}$ means that the contractor's received profit is gained by the below relation, that $\mathrm{x}$ is the project real cost in that.

$p=b+\rho_{c}\left(x_{0}-x\right)$

And $x \sim \operatorname{Gamma}(k, \theta) \sim \operatorname{Gamma}(24,103)$

So, $p=b+\rho_{c}\left(x_{0}-x\right)$ also has the GAMA dispensation with $\theta_{2}, k_{2}$ parameters, which we use the $\mathrm{x}$ dispensation average and variance and its relation with $\mathrm{p}$ dispensation average and variance.

Relation 15: $\mathrm{E}[\mathrm{p}]=\mathrm{b}+p_{c} x_{0 \_} p_{c} E[x]=k_{2} \theta_{2}$

Relation 16: $\operatorname{Var}[\mathrm{p}]=\mathrm{p}_{\mathrm{c}}{ }^{2} \operatorname{Var}(\mathrm{x})=k_{2} \theta_{2}^{2}$

Placing $\mathrm{E}(\mathrm{x})$ and $\operatorname{Var}(\mathrm{x})$ amounts the $\mathrm{P}$ dispensation average and variance will be gained based on $\boldsymbol{\rho}_{c}$ by (7) and (8) relations in the above relation.

Relation 17: $\mathrm{E}[\mathrm{p}]={ }^{k_{2}} \theta_{2}=300-472 p_{c}$

Relation 18: $\operatorname{Var}[\mathrm{p}]=\mathrm{k}_{2} \theta_{2}{ }^{2}=254616 \mathrm{p}_{\mathrm{c}}{ }^{2}$

The $\theta_{2}, k_{2}$ amounts have been calculated in table (7), for $\rho_{c}$ different amounts.
Table 7: C probability density function parameters for $\rho_{c}$ different amounts

\begin{tabular}{|c|c|c|c|c|c|c|c|c|c|c|c|}
\hline $\boldsymbol{\rho}_{c}$ & $\mathbf{0}$ & $\mathbf{0 . 1}$ & $\mathbf{0 . 2}$ & $\mathbf{0 . 3}$ & $\mathbf{0 . 4}$ & $\mathbf{0 . 5}$ & $\mathbf{0 . 6}$ & $\mathbf{0 . 7}$ & $\mathbf{0 . 8}$ & $\mathbf{0 . 9}$ & $\mathbf{1}$ \\
\hline$k_{2}$ & - & 25.1 & 4.151 & 1.095 & 0.304 & 0.064 & 0.003 & 0.007 & 0.037 & 0.076 & 0.116 \\
\hline$\theta_{2}$ & 0 & 10.072 & 49.536 & 144.668 & 366.354 & 994.594 & 5456.05 & -4104 & -2099 & -1652 & -1480 \\
\hline
\end{tabular}

The profit criterion utility, that is $\mathrm{u}(\mathrm{p})$, has been described as below in 2 parts: Relation 19: $\begin{cases}u_{1}(p)=-0.000005 p^{2}+0.004339 p-0.3230 & p \leq 400 \\ u_{2}(p)=0.000001 p^{2}-0.000852 p+0.8090 & p>400\end{cases}$

So, the contractor's expected profit utility is similar to cost expected utility.

Table 8: EUVp amounts for $\rho_{c}$ different amounts

\begin{tabular}{|c|c|c|c|c|c|c|c|c|c|c|c|}
\hline$\rho_{c}$ & 0 & 0.1 & 0.2 & 0.3 & 0.4 & 0.5 & 0.6 & 0.7 & 0.8 & 0.9 & 1 \\
\hline EUVp & - & 1.75 & 1.3554 & 1.003 & 0.7291 & 0.5553 & 0.4915 & - & - & - & - \\
\hline
\end{tabular}

Determining the proper proportion of risk cost allocation:

As far as, the aim of this dissertation is finding optimum $\rho_{c}$ and this is as that in the case of deflection, the contractive cost will be between the owner and contractor by a winner-winner relation, And clearly we can say that the under minded situation won't be gained for $\rho_{c}>0.6$ because the owner's profit gets negative and $\rho_{c}=0$ all the risk will be handled by owner. Table 9 , shows the cost expected utilities and the expected benefit by acceptable $\rho_{c}$.

Table 9: The cost expected utilities and the expected benefit by acceptable $\rho_{c}$

\begin{tabular}{|c|l|l|l|l|l|l|l|l|l|l|l|}
\hline $\boldsymbol{P}_{C}$ & 0 & 0.1 & 0.2 & $\mathbf{0 . 3}$ & 0.4 & 0.5 & 0.6 & $\mathbf{0 . 7}$ & 0.8 & 0.9 & 1 \\
\hline EUVc & 0.996638 & 0.997752 & 0.998680 & 0.999366 & 0.999780 & 0.999957 & 0.999997 & $\mathbf{1}$ & 1 & 1 & - \\
\hline EUVp & - & 1.7500 & 1.3554 & $\mathbf{1 . 0 0 3 0}$ & 07291 & 05533 & 04915 & - & - & - & - \\
\hline
\end{tabular}

Attention to table 9, how much the $\rho_{c}$ that is contractor's commonness proportion be more, the owner's expected utility will be more and reversely, the contractor's expected utility gets less. As far as we are looking for a proportion that can absorb the 2 sides consenting, then, in fact, we can say that our favorite point is the point that the absolute value of between the owner and contractor be in minimum.

Related to the data of above table $\rho_{c}=0.3$ and naturally $\rho 0=0.7$ are the proportion of risk allocation optima between owner and contractor, as this can absorb the consenting of the 2 sides and makes a winner-winner relation between them.

\section{Conclusion}

Respect to the importance of determining responsible in projects, for preventing the clashes, the increase in costs without reason and prices of contracts and/or the loss of 1 of the 2 sides, in the present research a calculative model was presented for determining the relation of specialization of non-controllable risk costs that this model can be used for determining the relation of risk between the owner and contractor, as the consenting of owner and contractor be made and make a winner-winner relation between them. None of the project members are responsible for noncontrollable risks ad there is no law for them. So this model uses the utility scale of doing the project for each of owner and contractors. the present model is able to measure the utility scale of investment or participation in doing a new project based on different criteria that play important roles in determining the consenting of each of the 2 sides And this model is responsible for each real cost deflection scale of the goal cost (contractive) as 1 continuous random variable and determining its probability dispensation under minding the real cost. This feature and calculation of expected utility value enables the owner and contractor till easily get ready for determining the relation of risk cost specialization in the contracting stage. other benefits of this model are the possibility of calculating the real cost of expected completion in every stage of doing the project, and by this quantity the contractor can predict the risk specialization relations which will have loss about it and avoids accepting them. 


\section{International Journal of Science and Research (IJSR) \\ ISSN (Online): 2319-7064}

Index Copernicus Value (2013): 6.14 | Impact Factor (2014): 5.611

\section{Presenting Topics for the Future Researches}

1) In this model, some discrete amounts are under minded for the relation of risk cost sharing that has been given in development of the model and could be solved in the continuous case.

2) The limit of proposed model has been limited to the risk allocation between the owner and contractor, as we can develop them to more members in the future researches for instance, the different contractors.

3) The mentioned model only under minds the scale of consenting between the owner and contractor for sharing the risk cost but this can place other factors in that like political problems, economical limitations and so on ..... .

4) In this model, the SAW technique has been used for making priority for attributes that we can use TOPSIS, LINMAP, MRS and .....

\section{Reference}

[1] "A Guide to the project Management Body of Knowledge (PMBOK Guide) ", an American National Standard ANSI/PMI 99-001-2004

[2] Konstantin's, K, "Risk Management: A powerful tool for improving utility of project oriented SMEs", Manufacturing Information Systems, 2002.

[3] K.C. Lam, D.Wang, Patrica T.K. Lee, Y.T. Tsang, "Modeling risk allocation decision in construction contracts", International Journal of Project Management 25, 2007, 485-493

[4] Chapman C, Ward S, "Project risk management: Processes, Techniques and Insights", John Wiley \& Sons Ltd, UK, Sussex, ISBN: 0-471-95804-2, 1997.

[5] Raz, T, and Michael, E, "Use and Benefits of Tools for Project Risk Management." International Journal of Project Management, Vol. 19, PP. 9-17, 2001.

[6] Richard, B, Lanza, CPA, "Reviewing a Project Risk Management System", AICPA, 2000. [7]. Srinivasa, R, Vinay, B, "Integrated risk management in case of tightly coupled software/hardware projects", STMicro electronics Private Limited, NOIDA, 2004.

[7] Michel Beuthe, Giuseppe Scannella, "Comparative analysis of UTA Multicriteria methods", European Journal of Operational Research 130, 2001, 246-262

[8] Office of Projects Management Process Improvement, "Project Risk Management Handbook", June 26, 2003.

[9] Kamal M Al-Subhi Al-Harbi, "Sharing Fractions in costplus-incentive-feecontracts", International Journal of Project Management, 1998, 73-80.

[10] "Enlightended risk allocation", The American council of engineering companies and the associated general contractors of America, February 1998.

[11] Aladpoosh, Hamid, "project Management Knowledge standard", Hami issuances, 2003.

[12] Asgharpour, Mohammad Javad, "Multiple Criteria Decision Making", Tehran University issuances, 1998.ephone, Inc.

\section{Author Profile}

Mr. Mohammad Ebrahim Ebrahimi Malekshah is M.A of Industrial Management, Planning \& Project Control manager of Hormoz Petrochemical in Iran. In 2009 he graduated from the Semnan Islamic Azad University, of Industrial Management in M.A and In 2007 he graduated from the Semnan Islamic Azad university, of Industrial Engineering in B.S. 